\title{
Acute milk-alkali syndrome
}

\author{
Bidhya Timilsina', Niranjan Tachamo', Prem Raj Parajuli' and Ilan Gabriely² \\ 1Department of Internal Medicine and 2Section of Endocrinology, Diabetes and Metabolism, Department of \\ Medicine, Reading Hospital, Reading, Pennsylvania, USA
}

Correspondence

should be addressed

to $\mathrm{N}$ Tachamo

Email

niranjantachamo@gmail.com

\section{Summary}

A 74-year-old woman presented with progressive lethargy, confusion, poor appetite and abdominal pain. She was found to have non-PTH-mediated severe hypercalcemia with renal failure and metabolic alkalosis. Extensive workup for hypercalcemia to rule out alternate etiology was unrevealing. Upon further questioning, she was taking excess calcium carbonate (Tums) for her worsening heartburn. She was diagnosed with milk-alkali syndrome (MAS). Her hypercalcemia and alkalosis recovered completely with aggressive hydration along with improvement in her renal function. High index of suspicion should be maintained and history of drug and supplements, especially calcium ingestion, should be routinely asked in patients presenting with hypercalcemia to timely diagnose MAS and prevent unnecessary tests and treatments.

\section{Learning points:}

- Suspect milk-alkali syndrome in patients with hypercalcemia, metabolic alkalosis and renal failure, especially in context of ingestion of excess calcium-containing supplements.

- Careful history of over-the-counter medications, supplements and diet is crucial to diagnose milk-alkali syndrome.

- Milk-alkali syndrome may cause severe hypercalcemia in up to $25-30 \%$ of cases.

\section{Background}

With the wide availability of over-the-counter (OTC) calcium preparation, routine treatment with calcium in osteoporosis, and the widespread use of calcium carbonate in patients with kidney failure, the incidence of MAS has increased in recent years. The prevalence is unknown, but according to some studies, it is estimated to be around $10 \%$ and can cause severe hypercalcemia in up to $25-30 \%$ of cases (1). The diagnosis, however, can be easily missed leading to unnecessary and expensive investigation and inappropriate treatment. Hence, careful medication history should be taken in hypercalcemic patients and corroborated by the family members, caregivers or primary care providers (2). In the current era, it is usually a consequence of the intake of calcium supplements or calcium-containing antacids and is also known as calcium-alkali syndrome (3).

\section{Case presentation}

A 74-year-old woman presented to the Emergency Department (ED) with progressive lethargy, confusion, poor appetite and abdominal pain for 10 days. She was constipated and was getting more depressed for which her family doctor had started her on mirtazapine few days back. Her medical history was significant for periprosthetic distal right femur fracture 10 weeks back for which she underwent surgical correction, which was complicated by acute blood loss requiring blood transfusions along with subsequent hypocalcemia and hypophosphatemia which corrected with adequate supplementation. Other relevant past medical history included osteoporosis, gastroesophageal reflux disease, hypertension, obstructive sleep apnea and anxiety/depression. Her medications 
included denosumab, cholecalciferol $2000 \mathrm{U}$ daily, dexlansoprazole, aspirin, amlodipine, sertraline and mirtazapine. She had received her 11 th dose of denosumab 3 months prior to the ED presentation. She was nonsmoker and consumed alcohol socially. There was no family history of hypercalcemia, kidney stones or other endocrinopathies.

In the ED, her vital signs included blood pressure $150 / 90 \mathrm{mmHg}$, pulse $101 / \mathrm{min}$, temperature $36.3^{\circ} \mathrm{C}$ and respiratory rate $12 / \mathrm{min}$ with oxygen saturation of $98 \%$ at room air. She was alert and oriented but had blunt affect with slow response and depressed mood. Physical examination was otherwise unremarkable.

\section{Investigation}

Relevant labs (Table 1 *No monoclonal proteins, no immunofixation ) included total serum calcium $15.1 \mathrm{mg} / \mathrm{dL}$ (Ref: $8.6-10.3 \mathrm{mg} / \mathrm{dL}$ ), ionized calcium $1.97 \mathrm{mmol} / \mathrm{L}$ (Ref: $\quad 1.15-1.33 \mathrm{mmol} / \mathrm{L}$ ), magnesium $1.3 \mathrm{mg} / \mathrm{dL}$

Table 1 Laboratory values during hospital admission.

\begin{tabular}{|c|c|}
\hline Parameters & Values \\
\hline Calcium & 15.1 \\
\hline Calcium, ionized & 1.97 \\
\hline Magnesium & 1.3 \\
\hline PTH & 6 \\
\hline PTHrP & 2.5 \\
\hline Vitamin D, 1,25-dihydroxy & 26.6 \\
\hline Vitamin D 25 hydroxy & 94.2 \\
\hline TSH & 0.74 \\
\hline (SPEP/IFE) & None* \\
\hline Albumin & 3.7 \\
\hline Total bilirubin & 0.5 \\
\hline Bilirubin, direct & 0.1 \\
\hline Alkaline phosphatase & 57 \\
\hline Total protein & 7.6 \\
\hline AST & 18 \\
\hline ALT & 8 \\
\hline WBC & 17.1 \\
\hline Hemoglobin & 11.3 \\
\hline Platelets & 512 \\
\hline Sodium & 131 \\
\hline Potassium & 4.1 \\
\hline Chloride & 91 \\
\hline $\mathrm{CO}_{2}$ & 33.4 \\
\hline Glucose & 114 \\
\hline BUN & 25 \\
\hline Creatinine & 1.60 \\
\hline Anion gap & 7 \\
\hline $\mathrm{pH}$ (venous) & 7.49 \\
\hline Phosphorus & 2.7 \\
\hline $\begin{array}{l}\text { Angiotensin-converting } \\
\text { enzyme }\end{array}$ & 21 \\
\hline CK & 39 \\
\hline CEA & 2.4 \\
\hline
\end{tabular}

(Ref: $1.9-2.7 \mathrm{mg} / \mathrm{dL}$ ), phosphorus $2.7 \mathrm{mg} / \mathrm{dL}$ (Ref: 2.5-5 mg/dL), albumin $3.7 \mathrm{~g} / \mathrm{dL}$ (Ref: $3.5-5.7 \mathrm{~g} / \mathrm{dL}$ ), PTH $6 \mathrm{pg} / \mathrm{mL}$ (Ref: 12-88 pg/mL), PTHrP $2.5 \mathrm{pmol} / \mathrm{L}$ (Ref: 0.0-3.4 pmol/L), 25-hydroxyvitamin D $94.2 \mathrm{ng} / \mathrm{mL}$ (Ref: $>20 \mathrm{ng} / \mathrm{mL}$ ), 1,25-dihydroxyvitamin D $26.6 \mathrm{pg} / \mathrm{mL}$ (Ref: $19.9-79.3 \mathrm{pg} / \mathrm{mL}$ ), TSH $0.74 \mu \mathrm{IU} / \mathrm{mL}$ (Ref: $0.45-$ $5.33 \mu \mathrm{IU} / \mathrm{mL}$ ). She had creatinine of $1.6 \mathrm{mg} / \mathrm{dL}$ (baseline $0.8-0.9 \mathrm{mg} / \mathrm{dL}$ ), venous $\mathrm{pH} 7.49$ (Ref: 7.32-7.43) and $\mathrm{CO}_{2}$ of $33.4 \mathrm{mEq} / \mathrm{L}$ (Ref: $21-31 \mathrm{mEq} / \mathrm{L}$ ). Other labs including serum sodium, potassium and liver function test were unremarkable. CT chest did not show any mass or lymphadenopathy concerning for malignancy or lymphoma. CT abdomen/pelvis few months back was negative for malignancy or lymphadenopathy. Her serum protein electrophoresis and immunofixation was negative ruling out multiple myeloma. Angiotensin-converting enzyme and creatinine kinase level were normal.

Review of her labs (serum calcium, bicarbonate and creatinine) 2 months back was normal. Upon further questioning, she admitted to taking excess tums (calcium carbonate), about 8-10 pills daily for several days, for her worsening heart burn. With her acute onset of hypercalcemia, metabolic alkalosis and renal failure with concomitant excess intake of tums, she was diagnosed with acute MAS.

Her 25-hydroxyvitamin D level was on the upper end of normal but toxic level is not considered unless it is $>150$. Malignancy, hyperparathyroidism, hypervitaminosis D, multiple myeloma and thyrotoxicosis were ruled out with appropriate labs and imaging.

\section{Treatment}

Her tums and vitamin D pills were discontinued. She was started on aggressive intravenous hydration (1 L normal saline bolus with NS infusion at $200 \mathrm{~mL} / \mathrm{h}$ ) with significant improvement in her symptoms and labs (serum calcium, ionized calcium, bicarbonate and creatinine improved to $11.47 \mathrm{mg} / \mathrm{dL}, 1.48 \mathrm{mmol} / \mathrm{L}, 29 \mathrm{mEq} / \mathrm{L}$ and $1.59 \mathrm{mg} / \mathrm{dL}$ respectively) over the next $18 \mathrm{~h}$. She received a total of $6 \mathrm{~L}$ NS over 3 days. She did not require any loop diuretic or bisphosphonate. She was treated with antibiotics for her Enterobacter fecalis UTI. For her iron deficiency anemia, she underwent upper endoscopy which revealed exudative esophagitis with non-erosive gastritis.

\section{Outcome and follow-up}

Her serum calcium and bicarbonate normalized by day 4 . She did not have any further episode of hypercalcemia. 
Her creatinine continued to improve and was 1.21 at discharge but her renal function did not recover to baseline even on extended follow-up (baseline estimated GFR was in 60s but improved only to 40s on follow-up, $\mathrm{Cr}$ remained stable at 1.2-1.3).

\section{Discussion}

MAS occurs due to excess ingestion of calcium and absorbable alkali (4). After its first identification about a century ago, MAS peaked in 1950s-1960s but significantly declined with the discovery of histamine-2 blockers and proton pump inhibitors. However, it has resurfaced again over the past 2-3 decades due to the wide availability of OTC calcium-containing supplements and medications (5). Since calcium has been added to many OTC products, juices, vitamin supplementations and even acetaminophen, there is always a possibility of inadvertent excess ingestion of calcium by consumers assuming that they are benign (6). Although ingestion of elemental calcium more than $4 \mathrm{~g}$ /day has been implicated in causing MAS, it can happen even with ingestion of calcium $<2 \mathrm{~g} /$ day, especially with concomitant intake of vitamin $\mathrm{D}$ and diuretics (1). Increased vitamin D intake results in enhanced intestinal calcium absorption causing the propensity to cause hypercalcemia even with lower calcium ingestion (3). Our patient was ingesting about $2.5 \mathrm{~g}$ of elemental calcium daily (1.6-2 $\mathrm{g}$ from her tums and $0.3-0.6 \mathrm{~g}$ from her dairy consumption) along with vitamin D.

MAS may present acutely, sub-acutely or chronically. Acute MAS presents with irritability, apathy, weakness, myalgia, vomiting, headache, etc. while chronic MAS presents with metastatic calcifications and nephrocalcinosis. Subacute form can have features of both (3). Key laboratory findings in MAS include hypercalcemia with metabolic alkalosis and impaired renal function (4). It is usually a moderate-to-severe PTHindependent hypercalcemia and is often associated with normal or low phosphorus levels, low magnesium levels and low 1,25-dihydroxyvitamin D levels (3). Careful history is often the key to diagnose MAS. History should include all OTC supplements as many patients do not recognize them as medications. So, patients may not elicit the history unless specifically asked (6). Our patient was not diagnosed with MAS until her second day of hospitalization when she was specifically asked about her tums ingestion.

MAS starts with decreased glomerular filtration due to renal vasoconstriction from hypercalcemia.
Hypercalcemia also causes direct damage to renal tubules and can induce nephrogenic diabetes insipidus with increased natriuresis and volume contraction. Alkalosis further impairs calciuresis perpetuating the cycle (7). Other possible mechanisms include activation of CaSR in the medullary thick ascending limb, causing inhibition of $\mathrm{Na}-\mathrm{K}-2 \mathrm{Cl}$ transport system and natriuresis (this could be exacerbated by alkalosis) and blockade of $\mathrm{ADH}$ mediated water reabsorption in the collecting duct (3). Factors that decrease the glomerular filtration rate such as chronic kidney disease, vitamin D supplementation, use of angiotensin-converting enzyme inhibitors (ACEI), angiotensin receptor blockers (ARB) further increase the risk of MAS. Use of hydrochlorothiazide decreases calciuresis and increases the risk of MAS (8). Our patient was not on ACEI, ARB or diuretics but she had poor oral intake which could have caused relative hypovolemia.

Management is usually supportive with adequate hydration and discontinuation of calcium-containing supplements (7). While symptoms and hypercalcemia resolve rapidly over days, it can take up to 6 months. Renal impairment, however, takes time to recover and may not recover completely. Approximately one-third of patients will develop permanent renal impairment (3). Bisphosphonates should not be used as first-line treatment as it does not decrease the duration of hypercalcemia but can cause hypocalcemia instead (1). Once calcium normalizes, PTH rebounds within hours and peaks in about 7 days (6). As MAS occurs due to excess ingestion of total calcium, it is recommended not to exceed a total calcium ingestion (diet plus supplements) of 1.2-1.5 g/day along with periodic monitoring (3).

Declaration of interest

The authors declare that there is no conflict of interest that could be perceived as prejudicing the impartiality of the research reported.

\section{Funding}

This research did not receive any specific grant from any funding agency in the public, commercial or not-for-profit sector.

\section{Patient consent}

Written informed consent has been obtained and is available for review on request.

Author contribution statement

B Timilsina and N Tachamo were involved in writing of the manuscript. P R Parajuli was involved in editing of the manuscript and direct patient care. 
Endocrinology

Diabetes \& Metabolism

CASE REPORTS
B Timilsina and others

Milk-alkali syndrome
ID: 18-0075; October 2018

DOI: $10.1530 / E D M-18-0075$
I Gabriely was involved in editing and finalizing of the manuscript as well as direct patient care.

\section{References}

1 Picolos Michalis K, Lavis Victor R \& Orlander Philip R. Milk-alkali syndrome is a major cause of hypercalcaemia among non-end-stage renal disease (non-ESRD) inpatients. Clinical Endocrinology 200563 566-576. (https://doi.org/10.1111/j.1365-2265.2005.02383.x)

2 Kaklamanos M \& Perros P. Milk alkali syndrome without the milk. BMJ 2007335 397-398. (https://doi.org/10.1136/bmj.39247.754676.BE)

3 Patel AM, Adeseun GA \& Goldfarb S. Calcium-alkali syndrome in the modern era. Nutrients 20135 4880-4893. (https://doi.org/10.3390/ nu5124880)
4 Medarov BI. Milk-alkali syndrome. Mayo Clinic Proceedings 200984 261-267. (https://doi.org/10.1016/S0025-6196(11)61144-0)

5 Beall DP, Henslee HB, Webb HR \& Scofield RH. Milk-alkali syndrome: a historical review and description of the modern version of the syndrome. American Journal of the Medical Sciences $2006331233-242$.

6 Gabriely I, Leu JP \& Barzel US. Clinical problem-solving. Back to basics. New England Journal of Medicine 2008358 1952-1956. (https:// doi.org/10.1056/NEJMcps0706188)

7 Ulett K, Wells B \& Centor R. Hypercalcemia and acute renal failure in milk-alkali syndrome: a case report. Journal of Hospital Medicine 2010 5 E18-E20. (https://doi.org/10.1002/jhm.579)

8 Yang JD, Lawson P \& Beland S. Severe hypercalcemia from the milk-alkali syndrome. American Journal of Medicine 2013126 e1-e2. (https://doi.org/10.1016/j.amjmed.2013.03.016)

Received in final form 14 August 2018

Accepted 3 October 2018 